\title{
Forearm Circumference
}

National Cancer Institute

\section{Source}

National Cancer Institute. Forearm Circumference. NCI Thesaurus. Code C100946.

A circumferential measurement of the largest part of the forearm. 